\title{
Phytochemical Profile and Antioxidant Activity of Nigella sativa L Growing in Morocco
}

\author{
Salima Tiji (D), ${ }^{1}$ Ouijdane Benayad, ${ }^{1}$ Mohamed Berrabah, ${ }^{2}$ Ibrahim El Mounsi, ${ }^{1}$ \\ and Mostafa Mimouni ${ }^{1}$ \\ ${ }^{1}$ Electrochemistry Team's Research, Applied Chemistry and Environment Laboratory (LCAE), Faculty of Sciences, \\ University Mohammed First (UMP), Oujda, Morocco \\ ${ }^{2}$ Solid Mineral Chemistry Team's Research, Applied Chemistry and Environment Laboratory (LCAE), Faculty of Sciences, \\ University Mohammed First (UMP), Oujda, Morocco
}

Correspondence should be addressed to Salima Tiji; salimatiji@gmail.com

Received 4 December 2020; Revised 3 April 2021; Accepted 7 April 2021; Published 20 April 2021

Academic Editor: Mehrbakhsh Nilashi

Copyright (c) 2021 Salima Tiji et al. This is an open access article distributed under the Creative Commons Attribution License, which permits unrestricted use, distribution, and reproduction in any medium, provided the original work is properly cited.

Background. Nigella sativa L (NS) is a powerful antioxidant and medicinal plant with many therapeutic applications particularly in traditional medicine for respiratory, gastrointestinal, rheumatic, and inflammatory disorders, as well as cancer. Objective. The aim of this study is to extract the active ingredients from the Moroccan Nigella sativa $\mathrm{L}$ and determine its antioxidant properties. We hypothesize that the separation of the compounds from Nigella sativa L has either a positive or negative effect on antioxidants. To study this, we explored different methods to simultaneously extract and separate compounds from Nigella sativa L and performed antioxidant tests ( $\beta$-carotene and DPPH) for all collected fractions. Methods. Nigella sativa L was hot-extracted by Soxhlet and mother extracts and was separated using silica column chromatography with adequate eluents. Qualitative phytochemical tests to determine the chemical families in Nigella sativa L seeds were performed on the fractions. They were also identified and characterized by GC-MS and HPLC-DAD. Then, antioxidant activity was examined by $\beta$-carotene bleaching and DPPH radical scavenger tests. Results and Conclusion. The mother extract hexane $\mathbf{F H}$ generated eight different fractions (SH1-8) and the acetone extract FA generated 11 fractions (SA1-11). The FH fractions had a high percentage of fatty acids, and the FA fractions had some interesting polyphenols derivative compounds. Phytochemical screening revealed secondary metabolites such as polyphenols flavonoids, alkaloids, steroids, terpenes coumarins, tannins, and saponins. We found that only two solvents (hexane, acetone) of different polarities could easily extract and simultaneously separate the components of Nigella sativa L. The antioxidant fractions that we collected had close activity to reference compounds but were more active than the corresponding mother extracts. Moreover, several $\mathrm{IC}_{50}$ values of fractions from acetone extract were better than those from hexane. Therefore, the antioxidant activity of Nigella sativa $\mathrm{L}$ is more attributed to flavonoids and polyphenols than fatty acids. In summary, the separation of hexane extract presents a more pronounced positive effect for antioxidant tests than acetone extract.

\section{Introduction}

Artificial antioxidants such as butylated hydroxytoluene (BHT) and butylated hydroxyanisole (BHA) are commonly reported for their efficiency in delaying cell deterioration but are also suspected to have negative health effects like carcinogenesis and toxicity [1]. Therefore, replacement with natural antioxidants could reduce health risks. Nigella sativa (NS) is a traditional and natural source of antioxidants $[2,3]$. In fact, NS is capable of free radical inhibition $[4,5]$ and can also significantly reduce oxidative stress $[6,7]$.

Nigella sativa, or black caraway, is a medicinal plant with many therapeutic uses in traditional Jordanian folklore. It is used to treat respiratory, gastrointestinal, rheumatic, and inflammatory disorders, as well as cancer $[8,9]$. It is also used to treat various respiratory disorders across the globe in Morocco, Pakistan, and Southern Europe [10]. 
The seeds of NS are used as a spice in bread, yogurt, marinades, sauces, and salads. In Islamic culture, NS is known as "El Habba Saouda" and is used in traditional medicine with reference to a proverb stating it is "a drug for all diseases except death." These words remained a mystery, until science was able to determine its therapeutic properties [11].

Considering the richness of its biological heritage, it is possible that the seed extracts could contain one or more active ingredients that specifically target each disease. Indeed, the diversity of secondary metabolites [12-14] can explain this variety of therapeutic uses.

Most previous studies explored the compounds hot- or cold-extracted with polar or nonpolar solvents as well as the essential oil $[15,16]$. These extracts contain a mixture of several families of chemical compounds; therefore it is highly unlikely that a single well-defined compound explains all therapeutic uses. In this work, we focus on two essential mother extracts that may contain distinct groups of secondary metabolites.

Hexane is a nonpolar solvent, which can only extract nonpolar compounds such as lipids (fatty acids). On the other hand, acetone is a polar solvent that can extract polar entities such as flavonoids and polyphenols. The use of a solvent of intermediate polarity (chloroform or ethyl acetate) that contains a mixture of the two groups of compounds is likely to inhibit separation. This study aimed to extract and separate these secondary metabolites simultaneously and evaluate their antioxidant activity. To the best of our knowledge, this is the first study to use chromatography to separate secondary metabolites of Moroccan Nigella sativa. To do this, we separated the mother extract, with known antioxidant activity, and generated several fractions, which in turn pass the antioxidant tests. Only those fractions exhibiting antioxidant activity moved forward with testing.

Migration of the compounds on TLC plates was used to determine the number of compounds, or groups of compounds, existing in the fraction, and was observed directly on the plates using a UV lamp. The GC-SM and HPLC-DAD analysis was used for compound identification and to explain the antioxidant activity of each fraction.

\section{Materials and Methods}

2.1. Chemical Reagents. All solvents and chemical compounds were purchased from Sigma Aldrich. Commercial organic solvents, hexane, chloroform, ethyl acetate, and acetone were of analytical grade ( 99.5\%). Chemical compounds (Silica gel, DPPH radical, $\beta$-carotene) used were of high purity. The phytochemical screenings used were TLC, Liebermann-Burchard, Mayer reagent, Dragendorff, and Folin-Ciocâlteu.

2.2. Plant Materials. The Nigella sativa seeds L used were harvested in Morocco during the last season and purchased from a local market at Oujda city. They were cleaned and ground in a blender to obtain a fine powder and stored in a dark place for future use.
2.3. Extraction. The powder was subjected to extraction using the following solvents: hexane, chloroform, ethyl acetate, and acetone. The extractions took place over 24 hours using a Soxhlet apparatus at $40-50^{\circ} \mathrm{C}$. The solvent was then evaporated on a rotavapor (BUCHI Rotavapor R-210) in vacuum rotary at $40^{\circ} \mathrm{C}$. The percentage of the extract yield was calculated using the mass of the seeds powder initially placed in the Soxhlet.

\subsection{Fraction's Separation by Column Chromatography.} Only two extracts were chosen for evaluation, those of hexane and acetone origin, due to the time-sensitive nature of separation by column chromatography. These two solvents were chosen because for their significant lipophilia gap; the difference of polarity would allow for simultaneous extraction and separation of compound groups with very varied physicochemical properties. In fact, hexane is a nonpolar solvent which promotes the solubility of hydrophobic compounds, while the polar solvent acetone solubilizes hydrophilic compounds.

Extracts were fractioned by silica gel column chromatography using 20\% hexane/80\% dichloromethane eluent system for hexane extract and 50\% cyclohexane/50\% dichloromethane eluent system for acetone extract. The dimensions of column chromatography were $6.5 \mathrm{~cm} \times 47 \mathrm{~cm}$ and the porosity of the silica gel was $60 \mathrm{~A}^{\circ}(63-200 \mu \mathrm{m})$.

\subsection{Identification Analysis}

2.5.1. Gas Chromatography Coupled to Mass Spectrometry (GC-MS) Analysis. Fraction investigation was performed on GC-MS using SHIMADZU instrument (GC-MS-QP2010) under computer control at $70 \mathrm{eV}$. About $1 \mu \mathrm{l}$ of every fraction was injected into the (GC) column $(30 \mathrm{~m} \times 0.25 \mathrm{~mm}$, $0.25 \mu \mathrm{m}$ ) under a flow rate of helium gas equal to $1.4 \mathrm{~mL} /$ min. Scanning continued for $28 \mathrm{~min}$ and the ionization temperature was maintained at $200^{\circ} \mathrm{C}$. The identification and quantification of the compounds were determined by comparing retention indices and spectral mass fragments with computer library NIST147 LIB [17].

\subsubsection{High Performance Liquid Chromatography Coupled} with Diode Array Detector (HPLC-DAD) Analysis. The identification of phenolic compounds in the acetone extract fractions was carried out on an analytical HPLC using Waters e2695 and diode array detector. Chromatographic separation was performed through a C18 column $(5 \mu \mathrm{m}, 250 \times 4.6 \mathrm{~mm})$. The solvents composition and the gradient elution process followed Mechraoui et al. [18] with some modifications. The elution was performed by a binary gradient system (A: water/ acetic acid $(2 \% \mathrm{v} / \mathrm{v})$ and $\mathrm{B}$ : acetonitrile, $\mathrm{pH}=2.6)$. The gradient process was $0-5 \mathrm{~min}$ : $95 \% \mathrm{~A}$ and $5 \% \mathrm{~B}$, then $25-30 \mathrm{~min}: 65 \% \mathrm{~A}$ and $35 \% \mathrm{~B}, 35-40 \mathrm{~min}: 30 \% \mathrm{~A}$ and $70 \% \mathrm{~B}$; and $40-45 \mathrm{~min}$ : $95 \%$ $\mathrm{A}$ and $5 \% \mathrm{~B}$. A flow rate of $0.9 \mathrm{~mL} / \mathrm{min}$ was used and $30 \mu \mathrm{L}$ fraction samples were injected after being passed through a $0.45 \mu \mathrm{m}$ filter. The UV detection was between 280 and $360 \mathrm{~nm}$ [18]. Phenolic compounds were identified by comparing retention time and UV-detection relative to the standards. 
2.5.3. Phytochemical screening. Phytochemical tests rely on specific revealers for each type of chemical family compound (steroids, alkaloids, and flavonoids). The principle of this method is based on visual observation of color change either by spraying the revealers directly on TLC plates or by adding a few drops of the revealers to the solution. These methods are described in detail by several authors in the literature $[19,20]$.

Phytochemical screening was performed with thin layer chromatography. TLC plates of silica gel supported by aluminum plates (fluorescent index $254 \mathrm{~nm}$ Fluka Analytical, Sigma-Aldrich) and eluents were used to achieve the separation. Different solvent developers were used with the reagents for the chemical screening.

Steroids/terpenes. Sterols were identified by Liebermann-Burchard reagent. $50 \mathrm{~mL}$ of ethanol was added to $5 \mathrm{~mL}$ of acetic anhydride and $5 \mathrm{~mL}$ of sulfuric acid on ice. The fraction characterization was performed using TLC plates pulverized at $100^{\circ} \mathrm{C}$ for $10 \mathrm{~min}$. [19].

Alkaloids. Mayer reagent (1 $\mathrm{g}$ of plant extract was placed with potassium mercury tetraiodide and water in a test tube) was used for the extraction of alkaloids. Precipitation would occur if the test was positive. Dragendorff reagent: potassium tetraiodobismuthate was pulverized on a TLC plate for fraction separation. Orange spots were detected by UV lamp at $365 \mathrm{~nm}$ [21].

Flavonoids. A solution of $\mathrm{AlCl}_{3}$ and $1 \%$ ammonium was pulverized on a TLC plate with the fraction. Yellow spots indicated flavones, blue spots showed phenolic acid, and red spots revealed the existence of Gallic acid [22].

Saponins. $2 \% \mathrm{SbCl}_{3}$ in chloroform solution was pulverized on a TLC plate with the fraction. Red fluorescent spots were detected at $254 \mathrm{~nm}$ by a UV lamp [20].

Polyphenols. Polyphenols were identified by Folin-Ciocâlteu reagent. On a TLC plate with the fraction, Folin-Ciocâlteu reagent was pulverized, and the spots were detected at $365 \mathrm{~nm}$ by a UV lamp.

Tannins. A solution of $2 \% \mathrm{FeCl}_{3}$ and acetic acid was pulverized on the fractions and placed on a TLC plate. Yellow spots were detected at $366 \mathrm{~nm}$ [21].

Coumarins. Coumarins were identified by two processes. First, a solution of $\mathrm{KOH} 2 \%$ was pulverized on a TLC plate or by a pulverized solution of $5 \%\left(\mathrm{CH}_{3} \mathrm{CO}_{2}\right) \mathrm{Pb}$ on $\mathrm{MeOH}$. The spots were visualized at $365 \mathrm{~nm}$ by a UV lamp [21].

\subsection{Antioxidant Activities}

2.6.1. $\beta$-Carotene Bleaching Test. This method was developed by Sun and Ho [23] and is based on the measure of absorbance at $470 \mathrm{~nm}$ due to the decomposition of linoleic acid. An emulsion of $\beta$-carotene-linoleic acid is prepared with Tween 20 and hydrogen peroxide. $2 \mathrm{mg} \beta$-carotene is dissolved in $10 \mathrm{~mL}$ chloroform. $1 \mathrm{~mL}$ of this solution is added to $20 \mu \mathrm{L}$ linoleic acid and $200 \mathrm{mg}$ Tween 40 . The chloroform is evaporated at $40^{\circ} \mathrm{C}$ under vacuum using a rotary evaporator and the residue is taken up to $100 \mathrm{~mL}$ by aerated distillated water with vigorous agitation. $4 \mathrm{~mL}$ of the emulsion is placed in a series of tubes containing $200 \mu \mathrm{L}$ samples of the fractions at different concentrations. The tubes are well shaken, and the absorbance is read at once at $470 \mathrm{~nm}$. The tubes are placed at $50^{\circ} \mathrm{C}$ for 120 minutes with a control, which contained only the emulsion and methanol. Absorbance was recorded and the inhibition percentage was expressed using equation (1). $\mathrm{IC}_{50}$ is the $50 \%$ inhibition concentration determined graphically on the $\% \mathrm{I}=f(C)$ curve by the extrapolation on the $X$-axis for the value of $Y=50 \%$ inhibition. $\mathrm{IC}_{50}$ was determined for the extracts and fractions. For $\beta$-carotene, the inhibition percentage was calculated according to the following equation:

$$
\mathbf{I} \%=\frac{\mathbf{A A}(120)-\mathbf{A C}(120)}{\mathbf{A C}(0)-\mathbf{A C}(120)} \times 100,
$$

where AA (120) is the absorbance at $120 \mathrm{~min}$; AC (120) is the control absorbance at $120 \mathrm{~min}$; and AC (0) is the control absorbance at $0 \mathrm{~min}$.

2.6.2. DPPH Radical Scavenging Activity. DPPH radical activity was carried out by the Gramza-Michalowska method [24]. DPPH is a stable radical, which has a free electron on the nitrogen atom. In the presence of antioxidant DPPH, the color changes from violet to yellow [25]. In this test, various concentrations of fractions were added to the methanol solution of DPPH radicals $(0.004 \% \mathrm{~m} / \mathrm{v})$. The samples were incubated for 30 minutes at room temperature and the absorbance was recorded at $517 \mathrm{~nm}$ against a blank solution. The percent inhibition was calculated using equation (2). The inhibitory concentration $\left(\mathrm{IC}_{50}\right)$ is determined as the concentration that inhibit $50 \%$ of DPPH $(\mathrm{I} \%=50)$. The inhibition percentage is calculated using the formula below:

$$
\mathbf{I} \%=\frac{(\text { Ac }- \text { Asample })}{\text { Ac }} \times 100,
$$

where Ac is the absorbance of DPPH without antioxidant (negative control) and Asample is the absorbance of DPPH in the presence of an antioxidant.

\section{Results and Discussion}

3.1. Extraction's Yield. In the successive extraction of the Nigella sativa L seeds (NS), the yields of mother extracts (FH and FA) were calculated relative to the mass of the starting powdered seeds placed in the Soxhlet apparatus. Hot extraction is more beneficial than cold extraction because the maceration and provides significantly higher yields [26]. In general, the color of the mother extracts obtained is more or less deep brown. The results show that the mother hexane extract, $\mathbf{F H}$, is the most abundant (34.2\%), while the acetone mother extract, FA, only represented $2 \%$. It can be underlined that NS contains essential fatty acid compounds (about 30\%). The final residue devoid of its chemical 
composition and probably consisting of fibers exhibits a $45.6 \%$ yield. This yield is similar to those of Khoddami et al. [27] (37.33\%) and Matthaus [28] (36\%.) However, Antuono et al. [28] obtained only $26 \%$ of NS in Moroccan seeds. Similarly, Sun and Ho [23] obtained comparative acetone extract yields at $2.5 \%$.

3.2. Hexane and Acetone Extracts Separation. Only two promising mother extracts from hexane $\mathbf{F H}$ and acetone FA were separated by silica gel chromatography. Separation was slow and fractions were collected every five min and systematically assessed on TLC plates.

Table 1 shows the yield of assembled fractions in relation to their respective mother extract. The yields were calculated relative to the mass of the mother extracts FH and FA used at the beginning. Following this procedure, the hexane mother extract generated eight fractions, SH1-8, and that for acetone fractions there were 11 fractions, SA1-11.

The eight fractions generated by hexane (Table 1) show varying yields with the highest being SH1 with 72.35\% followed by $\mathbf{S H 7}$ (9.11\%). The others give yields less than $5.12 \%$. The yields of fractions generated by acetone extract were calculated relative to the mass of the mother extract of acetone (FA) introduced at the beginning. SA1 represents the highest yield at $62.88 \%$ followed by SA11 at $15.82 \%$. The other fractions were all less than $10 \%$.

\subsection{GC-MS Analysis}

3.3.1. Hexane Extract. The results of $\mathbf{F H}$ characterization by GC-MS are presented in Figure 1 and Table 2. The recorded chromatogram after the extraction (Figure 1) shows the eminent presence of eight compounds. In Table 2, the chemical composition of $85.9 \%$ is identified as linoleic, palmitic, Hexadecanoic, and oleic acids.

We noted that, according to Table 2, the seeds from eastern Morocco mainly contain linoleic acid (80.26\%) and much less palmitic and oleic acid. This is in line with the work of several other authors [10, 27, 29-31].

The presence of other compounds was less than $6.24 \%$, but it should be noted that the majority of the compounds extracted had similar structures. It was also observed that the rest of the compounds extracted differed in the literature. This can be explained by spontaneous chemical reactions occurring as a result of physical conditions (i.e., light and temperature) without any experimental intervention.

In Morocco, Gharby et al. [29] reported $58.5 \%$ of oleic acid after extraction of esterified hexane extract, while Khodami et al. [27] showed that hexane extract of NS was mainly unsaturated fatty acids such as palmitic, linoleic, and oleic acids. Piras et al. [30] reported that Turkish NS contained 55\% unsaturated fatty acids. Unidentified components in the esterified hexane extract represented only $13 \%$. Those might be dependent on the esterification/methylation process. Ekowati et al. [31] and De Oliveira and Khater [10] reported many other compounds not found in our work.

3.3.2. Fractions of Hexane Extract. The identification results of fractions (SH1-8) from $\mathbf{F H}$ by GC-MS analysis are
TABLE 1: Yields of fractions derived from the mother extracts of hexane $\mathbf{F H}$ and acetone FA.

\begin{tabular}{lccc}
\hline $\begin{array}{l}\text { Hexane } \\
\text { Fraction }\end{array}$ & Yield/FH (\%) & Fraction & Yield/FA (\%) \\
\hline FH & 100 & FA & 100 \\
SH1 & 72.35 & SA1 & 62.88 \\
SH2 & 3.45 & SA2 & 9.92 \\
SH3 & 0.40 & SA3 & 3.30 \\
SH4 & 0.67 & SA4 & 3.55 \\
SH5 & 5.12 & SA5 & 0.15 \\
SH6 & 1.34 & SA6 & 2.31 \\
SH7 & 9.11 & SA7 & 1.16 \\
SH8 & 4.3 & SA8 & 0.42 \\
& & SA9 & 0.44 \\
& & SA10 & 0.05 \\
& & SA11 & 15.82 \\
\hline
\end{tabular}

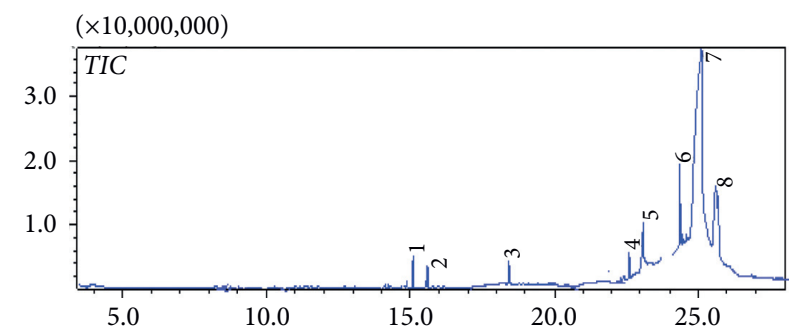

Figure 1: Gas chromatogram of the mother hexane extract FH.

presented in Table 3. The results indicate the presence of a considerable variety of compounds. We observed that the majority were fatty acids.

Several constituents were present in different fractions (e.g., palmitic acid identified in fractions SH1, SH2, SH3, SH5, SH6, SH7, and SH8; linoleic acid in SH1, SH2, SH5, and SH7 and oleic acid found in fractions SH3, SH6, and SH8. The appearance of fatty acids in many fractions could be explained by the disturbance of compounds migrating in the column because of the abundance of fatty acids. In fact, a high quantity of fatty acids and their derivatives migrated poorly in the column chromatography. To overcome this problem, we proceeded to centrifugation and then cooled the extract to $-4^{\circ} \mathrm{C}$ to separate the solid fat. Only $1.5 \%$ of the fatty acids were eliminated using this method.

In general, naturally extracted plant products are continuously transformed by oxidation or other chemicals reactions. Consequently, their percentage varies indefinitely despite good conservation. For example, olive oil retains its physicochemical characteristics for a whole year, but loses taste quality over time [32]. The variation of the quantity and quality of the hexane extract and fractions during migration in the chromatography column is justified. In addition, the chromatography column is slightly acidic, and the eluting solvents contain traces of transition metals, which can cause additional chemical reactions and transformations.

3.4. HPLC-DAD Analysis. The results of the HPLC analysis are presented in chromatograms (Figure 2) that show the constituents of the acetone extract and its fractions, while 
TABLE 2: Characterization by GC-MS of the chemical composition of the mother hexane extract of NS. TR: retention time; \%Air: percentage of compounds present.

\begin{tabular}{|c|c|c|c|c|c|c|c|c|}
\hline \multirow{2}{*}{$\mathrm{N}^{\circ}$} & \multirow{2}{*}{ Names } & \multicolumn{2}{|c|}{ This study } & \multicolumn{5}{|c|}{ Composition of references } \\
\hline & & TR & $\%$ Air & {$[29]$} & {$[30]$} & {$[27]$} & {$[31]$} & [10] \\
\hline 1 & 2.4-Decadienal & 15.10 & 1.79 & & & & 1.2 & \\
\hline 2 & 2-oxo-méthyl ester Hexadecanoic acid & 15.59 & 1.06 & & & & & \\
\hline 3 & Phenol. 4-methoxy-2.3.6-trimethyl- & 18.41 & 1.56 & & & & & \\
\hline 4 & Palmitic acid-methyl ester & 22.60 & 1.32 & 13.1 & $12-13 \%$ & 14.11 & 1.9 & \\
\hline 5 & Ascorbic acid 2.6-dihexadecanoate & 23.11 & 4.39 & & & & & \\
\hline 6 & Oleic acid methyl ester & 24.36 & 2.96 & 23.8 & $22 \%$ & 21.25 & & + \\
\hline 7 & Linoleic acid & 25.12 & 80.65 & 58.5 & $54-55 \%$ & 56.71 & 67.59 & + \\
\hline \multirow[t]{6}{*}{8} & E.Z-1.3.12-Nonadecatriene & 25.61 & 6.24 & & & & & \\
\hline & Stearic & & & 2.3 & $2-3 \%$ & & & \\
\hline & 9.12-Octadecadienoic acid (Z.Z)/cis linoleic acid & & & & & & 10.18 & \\
\hline & (9E.12E)-9.12-Octadecadienoic Acid & & & & & & 4.2 & \\
\hline & 9.12-heptadecadienoate & & & & & & 4.56 & \\
\hline & (9Z)-9.17-Octadecadienal & & & & & & 2.3 & \\
\hline
\end{tabular}

+Presence.

TABLE 3: Fraction chemical composition generated from the hexane mother extract and identified by GC-MS.

\begin{tabular}{|c|c|c|c|c|}
\hline Fraction & Pic number & Names & TR & \%Air \\
\hline \multirow{8}{*}{ SH1 } & 1 & 2.4-Decadienal & 15.11 & 4.95 \\
\hline & 2 & lauric acid & 18.68 & 1.87 \\
\hline & 3 & Palmitic acid & 22.61 & 8.64 \\
\hline & 4 & 17-bromopropanoic acid & 23.26 & 9.3 \\
\hline & 5 & 1-Octadecanol & 23.58 & 17.79 \\
\hline & 6 & Linoleic acid & 24.36 & 18.29 \\
\hline & 7 & Heptadecanoic acid & 24.64 & 11.02 \\
\hline & 8 & 9-Octadecanoic acid (Z). 2-butoxyethyl ester & 25.79 & 28.12 \\
\hline \multirow{8}{*}{$\mathrm{SH} 2$} & 1 & Octanoic acid. 8-hydroxy- & 16.23 & 2.61 \\
\hline & 2 & Methyl azelaaldehydate & 16.77 & 2.60 \\
\hline & 3 & Azelaic acid & 18.26 & 9.44 \\
\hline & 4 & Laural dimethyl acetal & 18.89 & 12.14 \\
\hline & 5 & Palmitic acid & 22.62 & 40.98 \\
\hline & 6 & Linoleic acid & 24.37 & 17.10 \\
\hline & 7 & 8-Octadecenoic acid & 24.43 & 1.25 \\
\hline & 8 & Heptadecanoic acid & 24.62 & 16.35 \\
\hline \multirow{4}{*}{$\mathrm{SH} 3$} & 1 & 2.4-Decadienal & 15.24 & 1.70 \\
\hline & 2 & Palmitic acid. Methyl ester & 22.60 & 5.65 \\
\hline & 3 & 1-Octadecanol & 23.84 & 87.32 \\
\hline & 4 & Oleic acid. Methyl ester & 24.34 & 5.31 \\
\hline \multirow{5}{*}{ SH4 } & 1 & Hexadecane. 7.9-dimethyl- & 15.17 & 9.97 \\
\hline & 2 & Hexadecane & 18.13 & 10.84 \\
\hline & 3 & Tricosanoic acid10.14.18.22-tetramethyl & 22.58 & 11.17 \\
\hline & 4 & 17 pentatriacontene & 24.59 & 60.37 \\
\hline & 5 & Lignocerol & 24.79 & 7.62 \\
\hline \multirow{5}{*}{ SH5 } & 1 & Hexadecane. 2.6.11.15-tetramethyl- & 17.55 & 0.29 \\
\hline & 2 & 9-Eicosene. $€-$ & 18.78 & 1.79 \\
\hline & 3 & Palmitic acid. Methyl ester & 22.60 & 2.65 \\
\hline & 4 & 9-Tricosene. (Z)- & 23.28 & 2.70 \\
\hline & 5 & linoleic acid & 24.05 & 92.54 \\
\hline \multirow{9}{*}{ SH6 } & 1 & Eicosane & 18.13 & 2.19 \\
\hline & 2 & Dichloroacetic acid.heptadecyl ester & 18.77 & 4.08 \\
\hline & 3 & 9-Dicosene & 21.14 & 5.12 \\
\hline & 4 & Palmitic acid. Methyl ester & 22.60 & 4.09 \\
\hline & 5 & 1-(+)-Ascorbic acid 2.6-dihexadecanoate & 23.03 & 14.37 \\
\hline & 6 & 9-Tricosene & 23.28 & 6.60 \\
\hline & 7 & 1-Octadecanol & 23.91 & 47.22 \\
\hline & 8 & Oleic Acid & 24.81 & 12.34 \\
\hline & 9 & 9-Hexacosene & 25.24 & 3.95 \\
\hline
\end{tabular}


TABLE 3: Continued.

\begin{tabular}{|c|c|c|c|c|}
\hline Fraction & Pic number & Names & TR & \%Air \\
\hline \multirow{10}{*}{ SH7 } & 1 & Hexadecane. 7.9-dimethyl- & 15.18 & 6.11 \\
\hline & 2 & Heptadecane. 8-methyl- & 15.18 & 3.71 \\
\hline & 3 & Hexadecane. 2.6.11.15-tetramethyl- & 17.55 & 8.44 \\
\hline & 4 & Pentanoic acid. 5-hydroxy-. 2.4-di-t-butylphenyl esters & 17.83 & 3.87 \\
\hline & 5 & Heptadecane. 2-methyl- & 18.13 & 11.68 \\
\hline & 6 & 9-Eicosene. $€$ - & 18.78 & 16.82 \\
\hline & 7 & Dichloroacetic acid.heptadecyl ester & 21.15 & 6.42 \\
\hline & 8 & Palmitic acid. Methyl ester & 22.60 & 18.89 \\
\hline & 9 & 9-Tricosene. $(\mathrm{Z})$ - & 23.28 & 9.74 \\
\hline & 10 & linoleic acid & 24.35 & 14.08 \\
\hline \multirow{8}{*}{ SH8 } & 1 & 2.4-Decadienal & 15.16 & 3.82 \\
\hline & 2 & 9-Eicosene. $€$ - & 18.77 & 16.53 \\
\hline & 3 & Dichloroacetic acid.heptadecyl ester & 21.14 & 16.84 \\
\hline & 4 & Palmitic acid. Methyl ester & 22.60 & 24.91 \\
\hline & 5 & 1-Octadecanol & 23.58 & 13.23 \\
\hline & 6 & Oleic acid. Methyl ester & 24.39 & 5.57 \\
\hline & 7 & Stearic acid. Methyl ester & 24.62 & 10.49 \\
\hline & 8 & 9-Hexacosene & 25.23 & 8.59 \\
\hline
\end{tabular}

TR: retention time; \%Air: percentage of compounds present.

Table 4 shows the identified constituents. On the $Y$-axis, the values of the peak's intensities are arbitrary. We can compare the intensities of the peaks on the same scheme, but we cannot compare them with the others because the collected fractions were concentrated each time by evaporation in a rotavapor. Therefore, we can only compare the position of the peaks in the chromatogram on the $X$-axis.

The acetone extract fractions gave different chromatograms compared to the hexane fractions. The peaks showed varying intensity depending on their abundance (Figure 2).

The FA contained a mixture of several compounds. Gallic acid is the major compound in Figure 2. It is also clearly visible in the SA1, SA2, and SA3 fractions. Our results are in agreement with those reported by Mechraoui et al. [18]. Except the kaempferol, all compounds found in the mother extract disappeared in the separated fractions. It should be noted that the separation was successful since, at the end, each fraction contained only one (SA1, SA4), two (SA3, SA7), or three (SA2, SA11) compounds. Due to technical problems, some fractions (SA5, SA6, and SA8) could not be analyzed and identified.

3.5. Phytochemical screening. Tables 5 and 6 summarize the results of the phytochemical screening for all hexane and acetone extract and fractions. The presence of phytochemical components of steroids, terpenes, coumarins, alkaloids, polyphenols, flavonoids, and saponins was determined.

The hexane mother extract had steroids, terpenes, tannins, saponins, and alkaloids (Table 5). However, coumarins, polyphenols, and flavonoids were absent. The acetone mother extract only contained polyphenols, steroids, tannins, flavonoids, and alkaloids (Table 6), while coumarins and saponins are not present.

Most fractions had alkaloids and saponins as well as several secondary metabolites like steroids and terpenes. Coumarins, polyphenols, and flavonoids appeared in some fractions despite their absence in the original extract (Table 5). This can be explained either by the phenomenon of opacity, where certain colors can be concealed by others, or by disparity of the color's wavelengths during measurements.

The phytochemical results of the NS hexane extract are similar to those reported by Javed [33], except in the absence of sterols in their hexane extract. Other phytochemical investigation [34] described close phytochemical screening to our results. Nevertheless, coumarins are reported and saponins were absent in our results.

Contrary to the hexane mother extract, the compound families in the acetone mother fraction were the same as those in the separation fractions (Table 6). The presence of polyphenols and flavonoids is marked in several fractions, and less for other chemical families. In contrast, some authors report that acetone extract has a high level of steroids and are low on coumarins [34].

3.6. $\beta$-Carotene Bleaching Test. Table 7 presents the values of the inhibitory concentrations necessary to reduce $50 \%$ oxidation $\left(\mathrm{IC}_{50}\right)$ by the antioxidant $\beta$-carotene. The values are given for both hexane and acetone mother extracts, as well as their corresponding fractions, which are compared with the reference value of butylhydroxyanisole (BHA). At the beginning, the quantity collected from certain fractions was extremely low. Hence, we could not perform totality tests of all fractions without exhausting our stock. All hexane fractions were more active than their mother extract $\mathbf{F H}$; however the acetone mother extract FA was more active than three of its fractions.

The activity of fractions from the hexane extract was dispersed as follows: SH4 $>$ SH1 $>$ SH7 $>$ FH. SH4 had the highest activity and resemblance to the reference BHA (Table 7), likely due to the presence of steroids and terpenes. Although SH1 and SH7 also contained steroids and flavonoids, they had a weak activity compared to SH4. This can be 

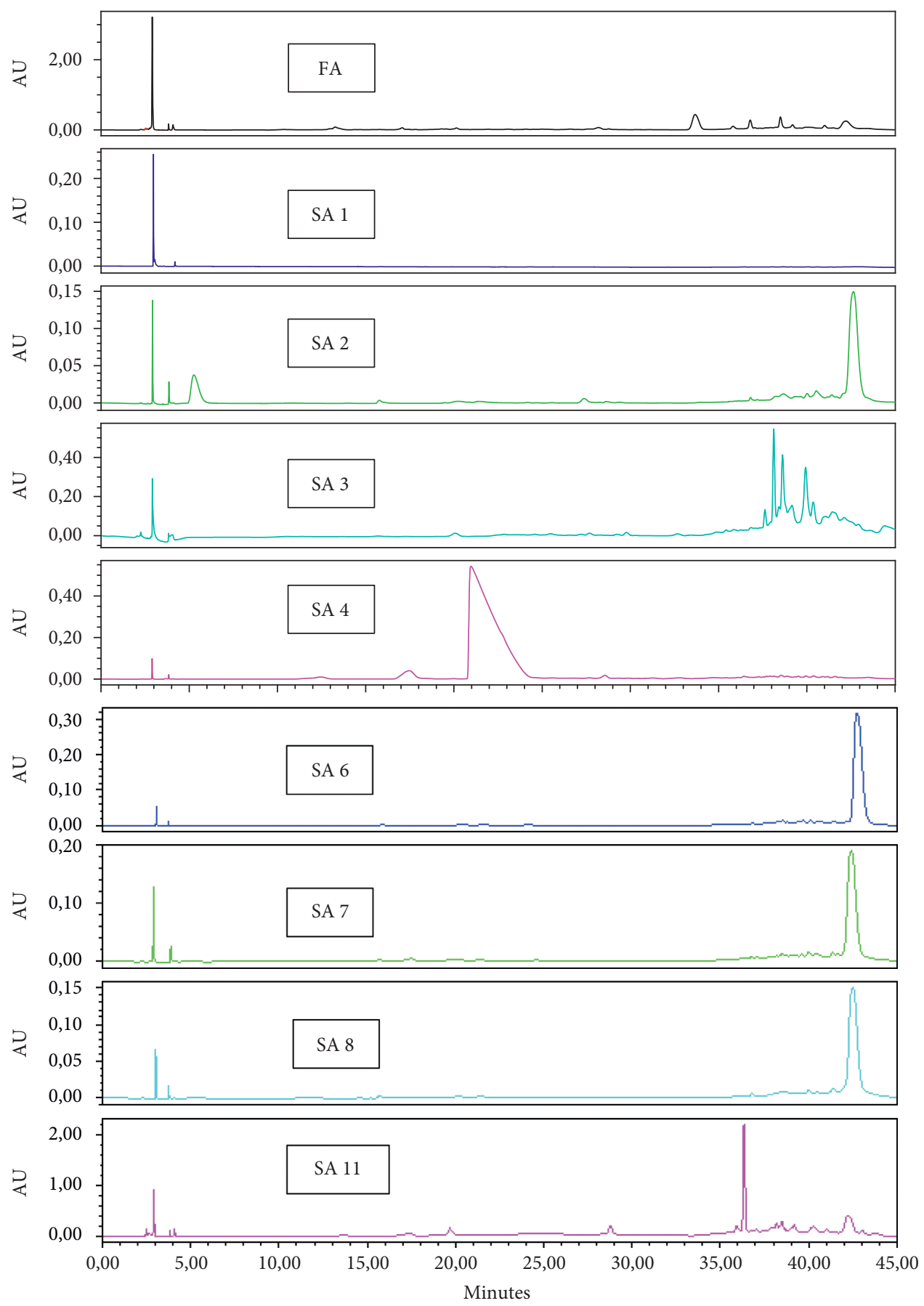

Figure 2: HPLC chromatograms fractions generated from the acetone mother extract FA.

attributed to the presence of other families of chemical compounds, which inhibit the apparent activity.

The characterization by GC-MS showed the existence of many antioxidant components [35], which have similar structure to BHA. In addition, derived terpenes were identified, such as 2.4-decadienal and (Z) 9-Tricosene. Moreover, fatty acid analogues, like linoleic acid, 17 pentatriacontene, or 2.4-decadienal, were also found. To support this claim, SH4, SH1, and SH7 were compared to vegetal species with high antioxidant activity like sage, thyme, and curcuma $[35,36]$. In the extract's lipids, the present antioxidant and anticancer phytosterols were also detected $[37,38]$.

In acetone extract and fractions, we observed that the inhibition activity is dispersed as follows: SA5 $>$ SA10 $>$ FA $>$ SA2 $>$ SA1 $>$ SA4. The first group of fractions composed of SA5 and SA10 had a much higher activity than FA with $\mathrm{IC}_{50}$ remarkably close to BHA (Table 7). The second group composed of SA2, SA1, and SA4 exhibited weaker antioxidant activities than FA.

Singh et al. [39] reported that FA was the most interesting part of NS because it has the highest antioxidant 
TABLE 4: Characterization by HPLC-DAD of fractions chemical compounds generated from the acetone mother extract FA.

\begin{tabular}{|c|c|c|}
\hline & Sample & Compounds \\
\hline 1 & FA & $\begin{array}{c}\text { Gallic acid } \\
\text { Hydroquinone } \\
\text { Apigenin } \\
\text { Naringenin } \\
\text { Ascorbic acid } \\
\text { Cysteine } \\
\text { Rutin. } \\
\text { Quercetin } \\
\text { Kaempferol }\end{array}$ \\
\hline 2 & SA1 & Gallic acid \\
\hline 3 & SA2 & $\begin{array}{c}\text { Gallic acid } \\
\text { Hydroquinone } \\
\text { Apigenin }\end{array}$ \\
\hline 4 & SA3 & $\begin{array}{c}\text { Gallic acid } \\
\text { Catechol }\end{array}$ \\
\hline 5 & SA4 & Naringenin \\
\hline 6 & SA5 & ND \\
\hline 7 & SA6 & ND \\
\hline 8 & SA7 & $\begin{array}{l}\text { Ascorbic acid } \\
\text { Cysteine }\end{array}$ \\
\hline 9 & SA8 & ND \\
\hline 10 & SA11 & $\begin{array}{c}\text { Rutin } \\
\text { Quercetin } \\
\text { L-Histidine }\end{array}$ \\
\hline
\end{tabular}

ND: not done.

TABle 5: Phytochemical screening of the hexane mother extract FH and its fractions.

\begin{tabular}{|c|c|c|c|c|c|c|c|}
\hline Fractions & Steroids\& terpenes & Coumarins & Alkaloids & Tannins & Polyphenols & Flavonoids & Saponins \\
\hline $\mathrm{FH}$ & +++ & - & + & ++ & - & - & ++ \\
\hline SH1 & + & ++ & +++ & - & +++ & + & - \\
\hline $\mathrm{SH} 2$ & - & + & + & - & ++ & - & - \\
\hline $\mathrm{SH} 3$ & + & - & - & - & - & - & ++ \\
\hline $\mathrm{SH} 4$ & + & - & - & - & - & + & - \\
\hline SH5 & - & - & - & - & - & + & ++ \\
\hline SH6 & + & - & - & ++ & - & - & - \\
\hline SH7 & + & +++ & - & ++ & ++ & ++ & - \\
\hline SH8 & - & - & - & - & - & + & ++ \\
\hline
\end{tabular}

$(-)$ absence; (+) low presence; $(++)$ moderated presence; $(+++)$ high presence.

TABle 6: Phytochemical screening of the acetone mother extract FA and its fractions.

\begin{tabular}{|c|c|c|c|c|c|c|c|}
\hline Fractions & Steroids\& terpenes & Coumarins & Alkaloids & Tannins & Polyphenols & Flavonoids & Saponins \\
\hline FA & ++ & - & + & ++ & +++ & + & - \\
\hline SA1 & - & - & - & - & + & + & - \\
\hline SA2 & - & - & - & - & ++ & + & - \\
\hline SA3 & - & - & - & - & +++ & ++ & - \\
\hline SA4 & - & - & - & - & ++ & + & - \\
\hline SA5 & - & - & - & - & + & ++ & - \\
\hline SA6 & - & - & + & + & - & - & - \\
\hline SA7 & + & - & - & - & - & - & - \\
\hline SA8) & + & - & - & + & - & - & - \\
\hline SA9 & + & - & - & - & - & + & - \\
\hline SA10 & & - & - & & + & + & - \\
\hline SA11 & ++ & - & ++ & + & + & + & - \\
\hline
\end{tabular}

$(-)$ absence; $(+)$ low presence; $(++)$ moderated presence; $(+++)$ high presence. 
TABLE 7: Antioxidant activity, $\beta$-carotene bleaching test of mother extracts of hexane and acetone, and their fractions.

\begin{tabular}{lccccccccc}
\hline Reference & Solvent & \multicolumn{7}{c}{$\beta$-Carotene bleaching test } \\
\hline BHA & Hexane & FH & SH1 & SH4 & SH7 & SH8 & - & - \\
$\mathbf{I C}_{\mathbf{5 0}} \mathrm{mg} / \mathrm{mL}$ & IC $_{\mathbf{5 0}} \mathrm{mg} / \mathrm{mL}$ & 56 & 13.2 & 1.02 & 14.1 & - & - & - \\
$\mathbf{0 . 0 5 3}$ & Acetone & FA & SA1 & SA2 & SA3 & SA4 & SA5 & SA10 & SA11 \\
& IC $_{\mathbf{5 0}} \mathrm{mg} / \mathrm{mL}$ & 3.72 & 7.36 & 4.46 & -- & 10.04 & 0.064 & 0.216 & -- \\
\hline
\end{tabular}

TABLE 8: Antioxidant activity of DPPH for hexane and acetone mother extracts and their fractions.

\begin{tabular}{|c|c|c|c|c|c|c|c|c|c|}
\hline \multirow{2}{*}{$\begin{array}{l}\text { Reference } \\
\text { Ascorbic acid }\end{array}$} & \multirow{2}{*}{$\begin{array}{c}\text { Solvent } \\
\text { Hexane }\end{array}$} & \multicolumn{8}{|c|}{$\mathrm{DPPH}^{\bullet}$ test } \\
\hline & & FH & SH7 & SH8 & & & - & - & - \\
\hline $\mathrm{IC}_{50} \mathrm{mg} / \mathrm{mL}$ & $\mathrm{IC}_{50} \mathrm{mg} / \mathrm{mL}$ & 23.25 & 16.01 & 8.7 & & & - & - & - \\
\hline 0.018 & Acetone & FA & SA1 & SA2 & SA3 & SA4 & SA5 & SA10 & SA11 \\
\hline & $\mathbf{I C}_{\mathbf{5 0}} \mathrm{mg} / \mathrm{mL}$ & 0.79 & 3.84 & 1.12 & 16.8 & 1.91 & 0.28 & 0.31 & 0.23 \\
\hline
\end{tabular}

activity. Mechraoui et al. [18] found that, in $\beta$-carotene tests, the $\mathrm{IC}_{50}$ from the acetone extract was $0.2444 \mathrm{mg} / \mathrm{mL}$. The $\mathrm{IC}_{50}$ value of pure gallic acid found by $\mathrm{Lu}$ and Khoo [40] $(10.50 \mu \mathrm{g} / \mathrm{mL})$ was different from that which we found in SA1 containing exclusively gallic acid. The $\mathrm{IC}_{50}$ for rutin is estimated to be $26.2 \mathrm{mg} / \mathrm{mL}$ by Yang et al. [41]. The only pure flavonoids like apigenin, quercetin, and naringenin gave interesting antioxidant activity $[42,43]$. This result can be extrapolated to the results found for fractions SA4, SA5, and SA10 since they only contain these flavonoids.

3.7. DPPH Radical Scavenging Activity. The values of $\left(\mathrm{IC}_{50}\right)$ determined by the DPPH antioxidant tests are summarized in Table 8. They were carried out for the hexane and acetone mother extracts, as well as their corresponding fractions, which were all compared with the reference value of ascorbic acid. $\mathrm{IC}_{50}$ of the hexane extract was the highest and the acetone mother extract was significantly lower than four of its fractions.

In the case of hexane, the $\mathbf{S H 7}$ and $\mathbf{S H 8}$ were more active than $\mathbf{F H}$, particularly $\mathbf{S H 8}$ whose $\mathrm{IC}_{50}$ was three times less. The antioxidant activity increases as follows: SH8 $>$ SH7 $>$ FH.

In the case of acetone, the activity value of the mother extract was intermediate between all fractions; the antioxidant activity increases in the direction SA11 $>$ SA5 $>$ SA10 $>$ FA $>$ SA2 $>$ SA4 $>$ SA1 $>$ SA3. The three most active fractions, SA11, SA5, and SA10, all had an $\mathrm{IC}_{50}$ lower than FA but not comparable to the reference ascorbic acid.

Considering the two antioxidant tests, $\beta$-carotene, and $\mathrm{DPPH}^{\bullet}$, the fractions from the acetone extract were more active than those from the hexane extract. For $\beta$-carotene, the best value was found in the acetone fraction SA5 with $\mathrm{IC}_{50}=0.064 \mathrm{mg} / \mathrm{mL}$, which is remarkably close to the BHA reference, which has a value of $\mathrm{IC}_{50}=0.053 \mathrm{mg} / \mathrm{mL}$. In the case of DPPH, all the acetone fractions showed acceptable $\mathrm{IC}_{50}$ values, particularly fractions SA5, SA10, and SA11 which had mean $\mathrm{IC}_{50}$ values around $0.25 \mathrm{mg} / \mathrm{mL}$. However, they are extremely far from the reference ascorbic acid $(0.018 \mathrm{mg} / \mathrm{mL})$.

Haroun [15] reported that NS hexane extract from two different places in the same country (Malaysia) gave
$\mathrm{IC}_{50}=8.17 \mathrm{mg} / \mathrm{mL}$ for NS harvested in Shah Alam and $\mathrm{IC}_{50}=4.48 \mathrm{mg} / \mathrm{mL}$ for NS harvested in Kentalan. In Yemen, $\mathrm{DPPH}$ test showed an $\mathrm{IC}_{50}=12.79 \mathrm{mg} / \mathrm{mL}$, in Sudan it was equal to $4.48 \mathrm{mg} / \mathrm{mL}$ [15], and in Ethiopia $\mathrm{IC}_{50}$ was $8.52 \mathrm{mg} /$ $\mathrm{mL}$. Soulaimanifar et al. [15] reported a very high $\mathrm{IC}_{50}$ value, $104.76 \mathrm{mg} / \mathrm{mL}$, in Iran. In Tunisia, Ksouda et al. [44] reported that NS hexane extract had $\mathrm{IC}_{50}=31 \mathrm{mg} / \mathrm{mL}$, a very close value to our $23.25 \mathrm{mg} / \mathrm{mL}$. The origin of the seeds and the extraction method are key factors for the quality and quantity of secondary metabolites. In Malaysia, the DPPH test on hexane extract by supercritical fluid extraction gave an $\mathrm{IC}_{50}=1.58 \mathrm{mg} / \mathrm{mL}[45]$.

SH7 antioxidant activity could be explained by its phytochemical analysis due to the presence of terpenes, steroids, polyphenols, and flavonoids in the fraction. Furthermore, GC-MS analysis gave diene functional groups and unsaturated fatty acids, which are known by their antioxidant activity. Palmitic acid is reported to have an antioxidant effect [46] on $\beta$-carotene test $[47,48]$; polyphenols derivatives like benzoic acid can also inhibit oxidation [47, 49]. SH7 and SH8 showed similar chemical compositions with fatty acids, and this may explain a part of their antioxidant activities.

The antioxidant activity of FA could be attributed to its flavonoids. HPLC-DAD identified gallic acid, hydroquinone, apigenin, naringenin, ascorbic acid, cysteine, rutin, quercetin, and kaempferol. Mechraoui et al. [18] reported an $\mathrm{IC}_{50}=0.1602 \mathrm{mg} / \mathrm{mL}$ from Tunisian NS. $\mathrm{IC}_{50}$ was $2.69 \mathrm{mg} /$ $\mathrm{mL}$ from a Pakistani NS. These results are different from ours with an $\mathrm{IC}_{50}$ equal to $0.79 \mathrm{mg} / \mathrm{mL}$.

The chemical structure of the fractions was identified by HPLC-DAD and the fraction's antioxidant activity was compared to commercial pure compounds. Pure commercial gallic acid $\mathrm{IC}_{50}$ was reported as $1.50 \mu \mathrm{g} / \mathrm{mL}$ [40], apigenin $\mathrm{IC}_{50}$ was $30.3 \mu \mathrm{g} / \mathrm{mL}$, rutin had an $\mathrm{IC}_{50}=23.7-50 \mu \mathrm{g} /$ $\mathrm{mL}[41,50]$, and quercetin presented with an $\mathrm{IC}_{50}=1 \mu \mathrm{g} / \mathrm{mL}$ [40]. These products are the essential compounds in fractions SA1, SA2, and SA11. It is clear that fractions of a single compound and fractions with multiple compounds do not have the same antioxidant activity level. There can be a positive synergistic effect on the activity or a negative one (inhibitor effect). If we compare the activity of SA1 and SA3, we can see that catechol in the presence of gallic acid has a 
negative effect on the antioxidant activity, whereas, in the case of SA2, hydroquinone and apigenin had a positive effect on activity. Therefore, testing is required to be able to predict the synergistic effects.

\section{Conclusion}

This study describes the simultaneous process of extractionseparation of chemical components of Nigella sativa L seeds based on the polarity of two well-chosen solvents. We have succeeded in extracting and separating two families of compounds with different physicochemical and phytochemical properties. Analysis and separation methods like GC-MS and HPLC-DAD allowed us to characterize and identify the majority of the mother extracts and separated fraction constituents. It should be noted that the Moroccan Nigella sativa $\mathrm{L}$ is rich in linoleic acid but low on oleic or palmitic acid.

Antioxidant activity was evaluated by $\beta$-carotene bleaching and DPPH scavenger. Antioxidant activity was attributed to each fraction and explained by its constituents. Nigella sativa L contains important secondary metabolites and is as a reliable source of antioxidant compounds. Moroccan NS gives a competitive $\mathrm{IC}_{50}$ compared to several countries around the world.

We show that secondary metabolite separation is beneficial for antioxidant activity. In fact, we repeatedly found that the fractions were more active than the mother extracts. In addition, some of the fractions had an underlined activity compared to the references.

We have succeeded to identify some of the interesting fractions generated by the mother extract and specified the compounds responsible for antioxidant activities. In fact, it can be said that, for $\beta$-carotene test, antioxidants are concentrated in hexane fractions SH4, SA5, and SA10. For DPPH test, fractions SH8, SA5, SA10, and SA11 include the active entities of Nigella sativa L. Future research should explore the active fractions in vitro and compare their antioxidant activity in animal models before and after induction of diseases caused by oxidative stress.

\section{Abbreviations}

$\begin{array}{ll}\text { NS: } & \text { Nigella sativa } \\ \text { FH: } & \text { Hexane extract } \\ \text { FA: } & \text { Acetone extract } \\ \text { SH1-8: } & \text { Fractions separated from hexane extract } \\ \text { SA1-11: } & \text { Fractions separated from acetone extract } \\ \text { GC-MS: } & \text { Gas chromatography coupled to mass } \\ & \text { spectroscopy } \\ \text { HPLC- } & \text { High performance liquid chromatography } \\ \text { DAD: } & \text { coupled to diode array detector. }\end{array}$

\section{Data Availability}

The data used to support the study are included within the article and are also available from the corresponding author.

\section{Conflicts of Interest}

The authors declare that they have no conflicts of interest.

\section{References}

[1] H. Kahl and R. Kappus, "Toxicology of the synthetic antioxidants BHA and BHT in comparison with the natural antioxidant vitamin E," Zeitschrift fur Leb. Untersuchung und -forsch.vol. 196, pp. 329-338, 1993.

[2] H. Schwartz, V. Ollilainen, V. Piironen, and A.-M. Lampi, "Tocopherol, tocotrienol and plant sterol contents of vegetable oils and industrial fats," Journal of Food Composition and Analysis, vol. 21, no. 2, pp. 152-161, 2008.

[3] S. Cheikh-Rouhou, S. Besbes, B. Hentati, C. Blecker, C. Deroanne, and H. Attia, "Nigella sativa L.: chemical composition and physicochemical characteristics of lipid fraction," Food Chemistry, vol. 101, no. 2, pp. 673-681, 2007.

[4] A.-S. Abedi, M. Rismanchi, M. Shahdoostkhany, A. Mohammadi, and A. M. Mortazavian, "Microwave-assisted extraction of Nigella sativa L. essential oil and evaluation of its antioxidant activity," Journal of Food Science and Technology, vol. 54, no. 12, pp. 3779-3790, 2017.

[5] D. Kadam and S. S. Lele, "Extraction, characterization and bioactive properties of Nigella sativa seedcake," Journal of Food Science and Technology, vol. 54, no. 12, pp. 3936-3947, 2017.

[6] P. Kumar, A. K. Patra, G. P. Mandal, and B. C. Debnath, "Carcass characteristics, chemical and fatty acid composition and oxidative stability of meat from broiler chickens fed black cumin (Nigella sativa ) seeds," Journal of Animal Physiology and Animal Nutrition, vol. 102, no. 3, pp. 769-779, 2018.

[7] H. M. Fahmy, E. Saad, N. M. Sabra, A. A. El-Gohary, F. F. Mohamed, and M. H. Gaber, "Treatment merits of Latanoprost/Thymoquinone-encapsulated liposome for glaucomatus rabbits," International Journal of Pharmaceutics, vol. 548, no. 1, pp. 597-608, 2018.

[8] G. Amin, Popular Medicinal Plants of Iran, pp. 1-66, Iranian Research Institute of Medicinal Plants, Tehran, Italy, 1991.

[9] G. Shafi, A. Munshi, T. N. Hasan, A. A. Alshatwi, A. Jyothy, and D. K. Lei, "Induction of apoptosis in HeLa cells by chloroform fraction of seed extracts of Nigella sativa," Cancer Cell International, vol. 9, no. 1, p. 29, 2009.

[10] D. R. De Oliveira and H. Khater, "The black seed, Nigella Sativa (Ranunculaceae), for prevention and treatment of hypertension," Metabolic Disorders: Hypertension, vol. 48, 2018.

[11] B. S. (Avicenne I. S. al-Sheikh, a.-R.A., al-Hussein Ben Ali, Le Canon de la Médecine. les médicaments simples (non composés). Avicenna. The Canon of Medicine, Kazi Publications, Chicago, IL, USA, 1999.

[12] F. A. Saleh, N. El-Darra, K. Raafat, and I. E. Ghazzawi, "Phytochemical analysis of nigella sativa L. Utilizing GC-MS exploring its antimicrobial effects against multidrug-resistant bacteria," Pharmacognosy Journal, vol. 10, no. 1, pp. 99-105, 2017.

[13] F. Bourgaud, S. Milesi, and E. Gontier, "Production of plant secondary metabolites: a historical perspective," Plant Science, vol. 161, no. 5, pp. 839-851, 2001.

[14] M. Grech-Baran and A. Pietrosiuk, "Artemisia species in vitro cultures for production of biologically active secondary metabolites," BioTechnologia, vol. 4, pp. 371-380, 2012.

[15] M. Soleimanifar, R. Niazmand, and S. M. Jafari, "Evaluation of oxidative stability, fatty acid profile, and antioxidant properties of black cumin seed oil and extract," Journal of Food Measurement and Characterization, vol. 13, no. 1, pp. 383389, 2018. 
[16] S. H. M. Aljabre, O. M. Alakloby, and M. A. Randhawa, "Dermatological effects of Nigella sativa," Journal of Dermatology \& Dermatologic Surgery, vol. 19, no. 2, pp. 92-98, 2015.

[17] J. Dobaria and S. Raval, "Separation of phytochemicals from peucedanum nagpurense by using separation of phytochemicals from peucedanum," Journal of Cell \& Tissue Research, vol. 15, pp. 5275-5281, 2016.

[18] O. Mechraoui, S. Ladjel, M. S. Nedjimi, and F. Technology, "Determination of polyphenols content, antioxidant and antibacterial activity of Nigella Sativa L. Seed polyphenolic extracts," Scientific Study and Research: Chemistry and Chemical Engineering, Biotechnology, Food Industry, vol. 19, no. 4, pp. 411-421, 2018.

[19] F. Belfekih, O. El, Y. Mariam, C. Lella et al., "Screening phytochimique D'Arbutus unedo L." The American Journal of Innovative Research \& Applied Sciences,vol. 5, no. 3, pp. 237-245, 2017.

[20] I. Louiz, F. Sellem, A. Tekitek, H. Langar, and A. El Abed, “"Étude des saponines isolées d'une espèce d'holothurie Holothuria tubulosa de la lagune de Bizerte," Bulletin de L'INSTM Salammbo, vol. 30, pp. 115-119, 2003.

[21] O. E. Yahyaoui, N. AIT Ouaaziz, I. Guinda et al., "Phytochemical screening and thin layer chromatography of two medicinal plants: Adansonia digitata (bombacaceae) and Acacia raddiana (fabaceae)," Journal of Pharmacognosy and Phytochemistry, vol. 6, no. 1, pp. 10-15, 2017.

[22] N. Dohou, K. Yamni, S. Tahrouch, L. Idrissi Hassani, A. Badoc, and N. Gmira, "Screening phytochimique d'une endémique ibéro-marocaine, Thymelaea lythroides," Bulletin de la Société de Pharmacie de Bordeaux, vol. 142, pp. 61-78, 2003.

[23] T. Sun and C. T. Ho, "Antioxidant activities of buckwheat extracts," Food Chemistry, vol. 90, no. 4, pp. 743-749, 2005.

[24] A. Gramza-michalowska, "Antiradical methods in evaluating antioxidant potential of preparations of plant origin," $\mathrm{Me}$ dicinal and Aromatic Plant Science and Biotechnology, vol. 1, no. 2, pp. 227-233, 2007.

[25] C. Popovici and I. Saykova, "Evaluation de l' activité antioxydant des composés phénoliques par la réactivité avec le radical libre DPPH," Génie Ind.vol. 15, pp. 26-39, 2009.

[26] M. Kiralan, G. Özkan, A. Bayrak, and M. F. Ramadan, "Physicochemical properties and stability of black cumin (Nigella sativa) seed oil as affected by different extraction methods," Industrial Crops and Products, vol. 57, pp. 52-58, 2014.

[27] A. Khoddami, H. M. Ghazali, A. Yassoralipour, Y. Ramakrishnan, and A. Ganjloo, "Physicochemical characteristics of nigella seed (nigella sativa L.) oil as affected by different extraction methods," Journal of the American Oil Chemists' Society, vol. 88, no. 4, pp. 533-540, 2011.

[28] B. Matthäus, "Antioxidant activity of extracts obtained from residues of different oilseeds," Journal of Agricultural and Food Chemistry, vol. 50, no. 12, pp. 3444-3452, 2002.

[29] S. Gharby, H. Harhar, D. Guillaume et al., "Chemical investigation of Nigella sativa L. seed oil produced in Morocco," Journal of the Saudi Society of Agricultural Sciences, vol. 14, no. 2, pp. 172-177, 2015.

[30] A. Piras, A. Rosa, B. Marongiu et al., "Chemical composition and in vitro bioactivity of the volatile and fixed oils of Nigella sativa L. extracted by supercritical carbon dioxide," Industrial Crops and Products, vol. 46, pp. 317-323, 2013.

[31] H. Ekowati, E. Prasasti, and U. Rastuti, "The active fraction from Nigella sativa and its activity against T47D cell line,"
Indonesian Journal of Chemistry, vol. 11, no. 3, pp. 217-222, 2011.

[32] L. Stoll, A. M. da Silva, A. Iahnke, T. M. H. Costa, S. H. Flôres, and A. d. O. Rios, "Active biodegradable film with encapsulated anthocyanins: effect on the quality attributes of extravirgin olive oil during storage," Journal of Food Processing and Preservation, vol. 41, no. 6, pp. 1-8, 2017.

[33] S. Javed, "Nutritional, phytochemical potential and pharmacological evaluation of nigella sativa (kalonji) and trachyspermum ammi (ajwain)," Journal of Medicinal Plants Research, vol. 6, no. 5, pp. 768-775, 2012.

[34] S. Ishtiaq, M. Ashraf, M. Q. Hayat, and M. Asrar, "Phytochemical analysis of nigella sativa and its antibacterial activity against clinical isolates identified by ribotyping," International Journal of Agriculture And Biology, vol. 15, no. 6, pp. 1151-1156, 2013.

[35] M. Suhaj, "Spice antioxidants isolation and their antiradical activity: a review," Journal of Food Composition and Analysis, vol. 19, no. 6-7, pp. 531-537, 2006.

[36] USDA, ARS, and National Genetic Resources Program, Phytochemical and Ethnobotanical Databases, National Germplast Resources Laboratory, Beltsville, ML, USA, [Online Database], 2003.

[37] A. De Jong, J. Plat, and R. P. Mensink, "Metabolic effects of plant sterols and stanols (Review)," The Journal of Nutritional Biochemistry, vol. 14, no. 7, pp. 362-369, 2003.

[38] C. C. Liolios, G. T. Sotiroudis, and I. Chinou, "Fatty acids, sterols, phenols and antioxidant activity of Phoenix theophrasti fruits growing in Crete, Greece," Plant Foods for Human Nutrition, vol. 64, no. 1, pp. 52-61, 2009.

[39] G. Singh, P. Marimuthu, C. S. De Heluani, and C. Catalan, "Chemical constituents and antimicrobial and antioxidant potentials of essential oil and acetone extract of Nigella sativa seeds †," Journal of the Science of Food and Agriculture, vol. 85, no. 13, pp. 2297-2306, 2005.

[40] C. Lu and T. J. Khoo, "Antioxidant activity determination of citronellal and crude extracts of cymbopogon citratus by 3 different methods," Journal of Pharmacy and Pharmacology, vol. 5, no. 5, pp. 395-400, 2014.

[41] J. Yang, J. Guo, and J. Yuan, "In vitro antioxidant properties of rutin," LWT-Food Science and Technology, vol. 41, no. 6, pp. 1060-1066, 2008.

[42] Y. C. Obermeier and R. E. White, "Effects of bioflavonoids on hepatic P450 activities," Xenobiotica, vol. 25, pp. 575-584, 1995.

[43] A. Sharma, A. K. Patar, and S. Bhan, "Cytoprotective , antihyperglycemic and antioxidative effect of naringenin on liver and kidneys of Swiss diabetic mice," International Journal of Health Sciences and Research, vol. 6, pp. 118-131, 2016.

[44] G. Ksouda, M. Hajji, S. Sellimi et al., "A systematic comparison of 25 Tunisian plant species based on oil and phenolic contents, fatty acid composition and antioxidant activity," Industrial Crops and Products, vol. 123, pp. 768-778, 2018.

[45] N. K. Mohammed, M. Y. Abd Manap, C. P. Tan, B. J. Muhialdin, A. M. Alhelli, and A. S. M. Hussin, “"The effects of different extraction methods on antioxidant properties, chemical composition, and thermal behavior of black seed (nigella sativa L.) oil," Evidence-based Complementary and Alternative Medicine, vol. 2016, Article ID 6273817, 10 pages, 2016.

[46] P. P. Kumar, S. Kumaravel, and C. Lalitha, "Screening of antioxidant activity, total phenolics and GC-MS study of 
Vitex negundo," African Journal of Biochemistry Research, vol. 4, no. 7, pp. 191-195, 2010.

[47] S. Kim, S. Jeong, W. Park, K. Nam, D. Ahn, and S. Lee, "Effect of heating conditions of grape seeds on the antioxidant activity of grape seed extracts," Food Chemistry, vol. 97, no. 3, pp. 472-479, 2006.

[48] H. Matsufuji, H. Nakamura, M. Chino, and M. Takeda, "Antioxidant activity of capsanthin and the fatty acid esters in paprika (capsicumannuum)," Journal of Agricultural and Food Chemistry, vol. 46, no. 9, pp. 3468-3472, 1998.

[49] M. N. Coleman, "The functional morphology and evolution of the primate auditory system," Journal of Agricultural and Food Chemistry, vol. 1, pp. 1453-1459, 2007.

[50] F. Sharififar, G. Dehghn-Nudeh, and M. Mirtajaldini, "Major flavonoids with antioxidant activity from Teucrium polium L," Food Chemistry, vol. 112, no. 4, pp. 885-888, 2009. 